\title{
Análisis del ciclo de vida en la industria de harina y aceite de pescado en plantas pesqueras de Huacho, Carquín y Vegueta, Huaral, Lima, 2018-2019
}

\author{
Analysis of the life cycle applied in the fishmeal and fish oil industry in fishing \\ plants in Huacho, Carquín and Vegueta, Huaral, Lima, 2018-2019
}

\author{
Carlos Cabrera Carranza ${ }^{1}$, Arístides Sotomayor Cabrera ${ }^{2}$, Verónica Espinel Pino ${ }^{3}$
}

Recibido: 01/07/2020 - Aprobado: 30/10/2020 - Publicado: 30/11/2020

\begin{abstract}
RESUMEN
La fabricación de harina de pescado, es una de las principales actividades productivas del pais, sin embargo, son elevados los volumenes de residuos organicos vertidos al ambiente marino. Se aplica el análisis del ciclo de vida (ACV) y se pone énfasis en los residuos líquidos en plantas pesqueras de Huacho, Carquín y Vegueta en Huaral. Lima. La investigación es aplicada, descriptiva y comparativa, desarrolla un enfoque cualitativo - cuantitativo. Según la Norma ISO 14001 (Miranda, 2018), los aspectos ambientales significativos identificados destacan el recibir y almacenar la materia prima, cocción, desaguado, prensar, separar, centrifugar, moler, secar, dosificar antioxidante, ensaque, generación de energía, evaporar el agua de cola, tratar los caldos, tratar los efluentes industriales, mantenimiento de maquinaria. En el balance de materia y energía para una planta de $84 \mathrm{TM} /$ hora, el rendimiento de producción es pescado /harina: 4.150 y para pescado /aceite: 6.307 . El principal impacto está asociado con los volúmenes vertidos de agua residual que contiene carga orgánica, que incrementan la concentración de solidos suspendidos, grasas y aceites y demanda bioquímica de Oxígeno, que sobrepasan el límite máximo permisible (LMP).
\end{abstract}

Palabras claves: Análisis del ciclo de vida; harina de pescado; aspectos ambientales; impacto ambiental.

\begin{abstract}
The fish oil and flour industry is one of the main productive activities in the country, however, the volumes of organic waste discharged into the marine environment are high. Life Cycle Analysis (LCA) is applied with an emphasis on liquid residues in fishing plants in Huacho, Carquín and Vegueta in Huaura. Lime. The research is applied, descriptive and comparative, it develops a qualitative - quantitative approach. According to ISO 14001, the significant environmental aspects identified include the reception and storage of raw materials, cooking, draining, pressing, separation, centrifugation, grinding, drying, dosing of antioxidant, bagging, energy generation, evaporation of cola water, broth treatment, industrial effluent treatment, machinery maintenance. In the matter and energy balance for a plant of $84 \mathrm{MT} /$ hour, the production yield is fish / flour: 4,150 and for Fish / Oil: 6,307. The main impact is associated with the volumes of waste water discharged containing organic load, which increase the concentration of suspended solids, fats and oils and biochemical oxygen demand, which exceed the maximum permissible limit (LMP).
\end{abstract}

Keywords: Analysis of the life cycle; fishmeal; environmental aspects; environmental impact.

1 Profesor principal. Universidad Nacional Mayor de San Marcos, Facultad de Ingeniería Geológica, Minera, Metalúrgica y Geográfica, Departamento de Ingeniería Geográfica. Lima, Perú. Autor para correspondencia: ccabrerac@unmsm.edu.pe ORCID: https://orcid.org/0000-0002-5821-5886

2 Profesor principal. Universidad Nacional Mayor de San Marcos, Facultad de Ingeniería Geológica, Minera, Metalúrgica y Geográfica, Departamento de Ingeniería de Minas. Lima, Perú. E-mail: asotomayorc@unmsm.edu.pe ORCID: https://orcid.org/0000-0001-9488-860X

3 Docente de la Universidad Técnica de Manabí. Ecuador. E-mail: vespinel@utm.edu.ec ORCID: https://orcid.org/0000-0002-7604-7599 


\section{INTRODUCCIÓN}

La presente investigación tiene como objeto aplicar el Análisis dcl Ciclo de vida (ACV) en la industrialización de la industria de harina y aceite en plantas de Huacho, Carquín y Vegueta en Perú. En el Perú, la industria de harina y aceite de pescado se inició a mediados de los años cincuenta, impulsado por la reconstrucción europea y en particular por la política de seguridad alimentaria que desarrolló Alemania en la postguerra, donde la especie Engraulis ringens fue extraída y destinada a la producción de harina de pescado. Según Talledo (2010), en el mundo el primer país que destaca como principal exportador de harina de pescado es el Perú, también ratifica que no hay pesquería tan grande como la de Engraulis ringens (anchoveta), llegando a volúmenes de captura de seis millones de toneladas métricas.

Las actividades humanas tienden a reducir la complejidad de los sistemas ecológicos, es así como los residuos líquidos de la industria de harina y aceite de pescado, cuando no son tratados en forma sostenible y se vierten al cuerpo receptor (mar), generan impactos ambientales negativos, es así como estos cambios ambientales se manifiestan a menudo más rápidamente que la evolución biológica orgánica.

El análisis del ciclo de vida del producto es un instrumento de gestión estratégica aplicada al ambiente de manera preventiva y está integrada al proceso productivo y servicios para aumentar la eficiencia y minimizar riesgos a la salud humana y al ambiente. Asimismo, es vital cumplir con la normatividad ambiental y la implementación de estrategias de gestión ambiental para obtener mejores beneficios que mejoren la calidad de vida de la población, permitiendo que el sector empresarial obtenga beneficios tangibles

La investigación tiene un enfoque holístico de nivel cualitativo-cuantitativo. Este enfoque permite encontrar estrategias ambientales para reducir los niveles de polución del ambiente marino por residuos industriales líquidos que vienen de fabricación de harina y aceite de pescado en Huacho, Vegueta y Carquín.

\section{MÉTODOS}

El estudio es de investigación aplicada, descriptiva y comparativa, utiliza como instrumento de gestión ambiental, el análisis del ciclo de vida (ACV). Se realizó en plantas pesquera dedicadas al proceso de harina de pescado en Carquín, Vegueta, Huacho de la provincia de Huaral. Lima (Figura 1). Se tomaron en cuenta a las cuatro principales empresas pesqueras del área de estudio, TASA, Hyduck, Exalmar y Productos del Campo.

Entre las principales técnicas e instrumentos utilizadas destacan la aplicación de la Norma ISO 14040:2006 (CTN 150 - Gestión Ambiental, 2006). Evaluación del ciclo de vida. Principios y marco. el Marco normativo nacional y se compara con el Marco legal internacional, archivos de controles y monitoreo ambiental. Se toma en cuenta informes de Monitoreo de las empresas TASA, Hyduck, Exalmar y Productos del Campo, OEFA, IMARPE, Ministerio de la Producción. Se emplearon técnicas de observación y revisión documental.

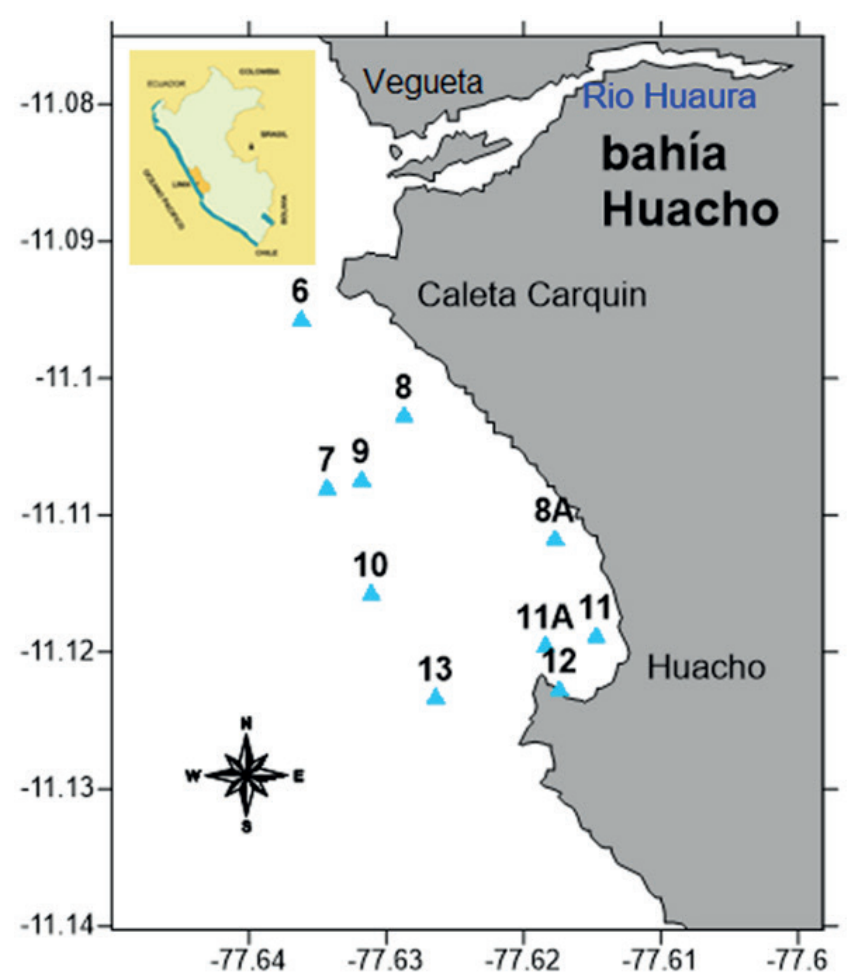

Figura 1. Carta de posiciones de muestreo y lugares donde se ubican las fábricas de harina de pescado 2018-2019, Huacho.

Fuente: IMARPE (Instituto del Mar del Perú, 2019) 


\section{RESULTADOS}

\subsection{Límites del sistema}

La unidad funcional estuvo dada por $84 \mathrm{t} / \mathrm{h}$ de materia prima (pescado) y se pusieron límites al sistema para aplicar el Análisis al proceso productivo de harina y aceite de pescado, el cual se muestra en el diagrama de flujos (Figura 2).

\subsection{Análisis del inventario}

\subsubsection{Desembarque de recursos marítimos}

Las capturas máximas de anchoveta llegaron a 7500000 toneladas métricas durante los años 2004 y 2005. Durante el 2011 llegaron a capturarse 6175000 toneladas y durante el 2014, los desembarques llegaron a 2530000 toneladas, lo cual representó una merma del $41,9 \%$, con respecto al año 2013, IMARPE (Zuta \& Guillén, 1970).

Según el D.S. $\mathrm{N}^{\circ}$ 010-2008 (PRODUCE, n.d.), el desembarque por la industria de consumo humano indirecto (harina-aceite), durante el 2017, fue de 3208545 de TM, que respecto al año 2016 representa una cantidad superior en 422,69 miles de TM (15,17\%), impulsado por el incremento en $15,52 \%$ del recurso anchoveta como efecto de la presencia de condiciones oceanográficas favorables de nuestro litoral durante el primer semestre, en el cual se logró el 93,7\% del desembarque anual. Observándose que, del total desembarcado, el 73,6\% se descargó en los establecimientos ubicados en los puertos de Chicama (21,1\%), Chimbote
(16,8\%), Pisco $(14,4 \%)$, Callao $(9,8 \%)$, Chancay $(5,8 \%)$ y Coishco (5,7\%), mientras que, en la zona de estudio, en Carquín (3.17 \%) y Vegueta $(2.18$ \%). Así mismo; durante el año 2017 en los puertos de Vegueta y Carquín, se dieron los desembarques de anchoveta llegando al máximo de 26,447 TM en Vegueta y de 23173 TM en Carquín.

De acuerdo a IMARPE (Instituto del Mar del Perú, n.d.), durante el año 2018, los desembarques en el puerto de Vegueta fluctuaron entre 9453.3 TM en el mes de junio y 99, 938.9 TM en el mes de mayo, también, en el puerto de Carquín, los desembarques de anchoveta llegaron a un máximo de 64,103.9 TM en el mes de mayo.

Según el IMARPE 2019 (Instituto del Mar del Perú, n.d.-b) de monitoreo de efluentes para la planta Exalmar en Carquín, los volúmenes desembarcados de materia prima (anchoveta), durante 2018-2019 oscilaron entre 290.955 TM en diciembre 2019 y 2234.055 TM en noviembre 2018; estos datos sirvieron de base para detallar el impacto que originan los residuos líquidos en el cuerpo receptor (mar).

3.2.2 Identificación y evaluación de aspectos ambientales

Teniendo en cuenta la naturaleza de los objetivos de la presente investigación, se consideran los aspectos ambientales significativos poniéndose énfasis en la línea de residuos industriales líquidos: recibir y almacenar la materia

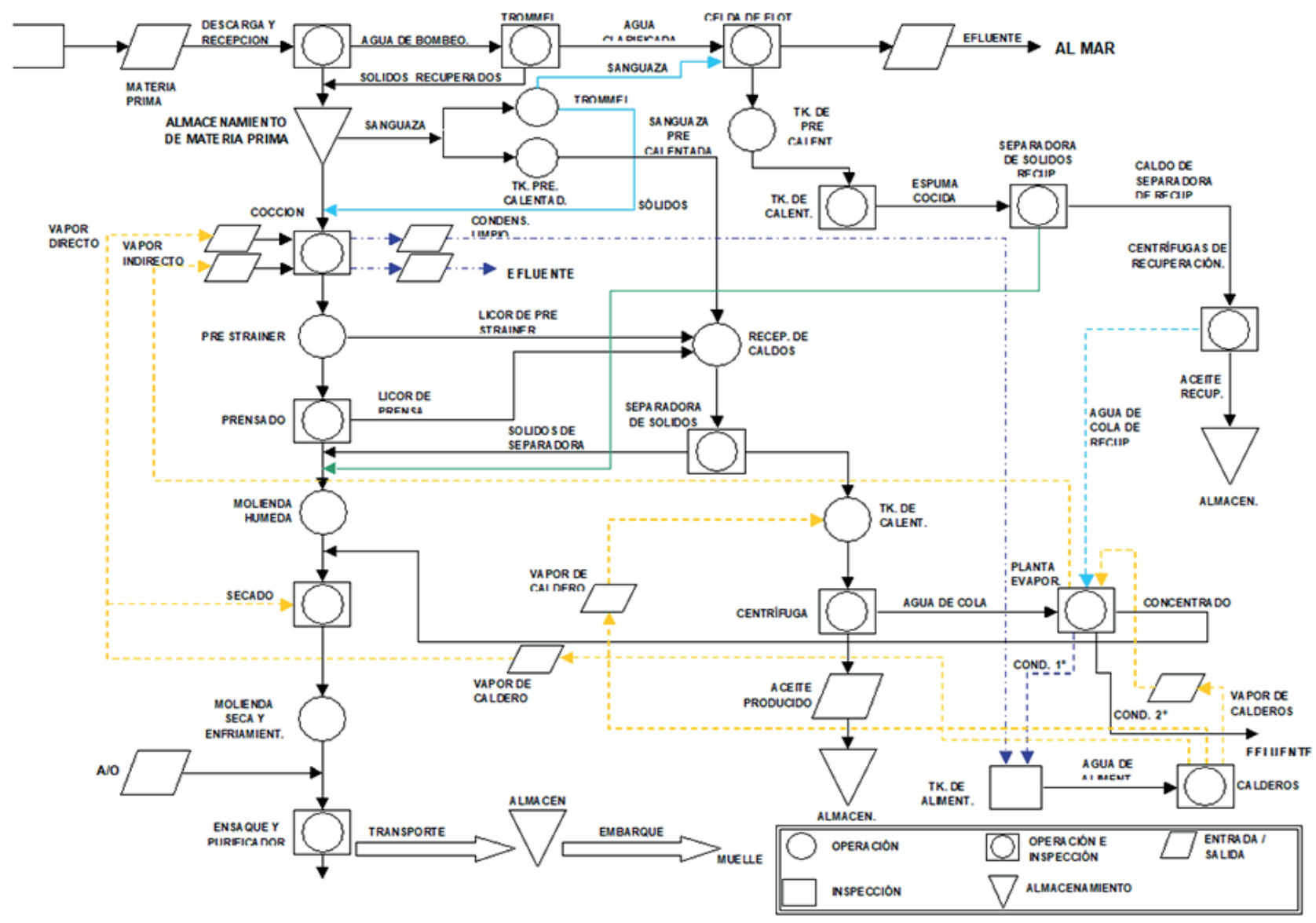

Figura 2. Flujograma del procesamiento en la industria de harina y aceite de pescado 
prima, cocinado, desaguado, prensar, separar, centrifugar, moler, secar, dosificar antioxidante, ensaque, generación de energía, evaporar el agua de cola, tratar los caldos, tratar los efluentes industriales y mantenimiento de maquinaria.

\subsubsection{Balance de materia del proceso de elaboración} de harina y aceite de pescado

En la Tabla 1 se presenta el balance de materia para una línea de procesos de $84 \mathrm{TM} /$ hora, encontrando el rendimiento de producción es de pescado /harina: $4.150 \mathrm{y}$ para pescado /aceite: 6.307 .

Tabla 1. Consolidado del Balance de materia. Exalmar. Huacho

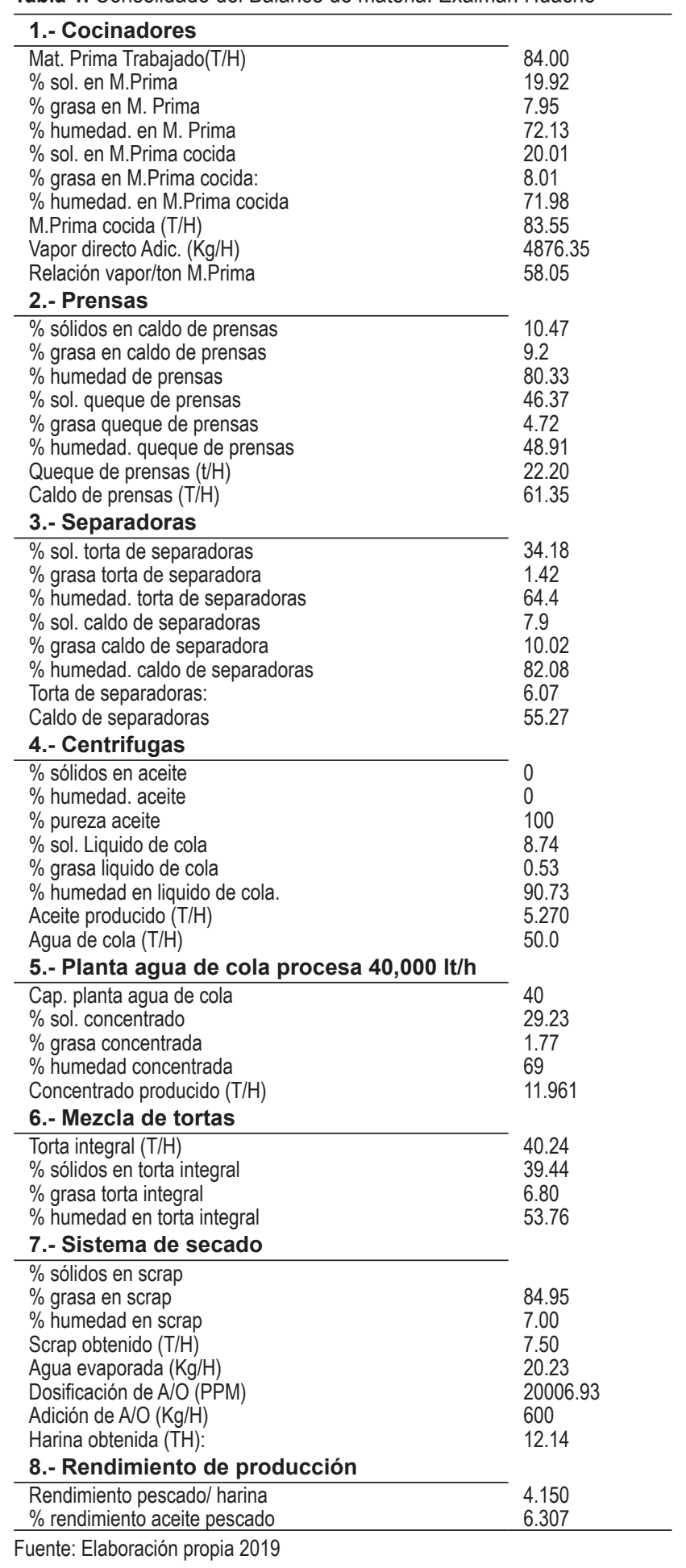

3.2.4 Potencial impacto ambiental de las aguas residuales de la industria de harina y aceite de pescado

Se presentan los resultados del análisis de efluente de la planta pesquera Exalmar, obtenido durante los años 20182019 y su comparación con los LMP establecidos mediante D.S. No 010-2018 (MINAM, 2018). Las concentraciones de grasas y aceites oscilaron entre $3.75 \mathrm{mg} / 1$ y $38.4 \mathrm{mg} / \mathrm{l}$ para abril y junio, no llegando a sobrepasar el LMP que es equivalente a $350 \mathrm{mg} / \mathrm{l}$. (Figura 3), los sólidos suspendidos totales (SST) estuvieron en el rango de $96.5 \mathrm{mg} / 1$ y 785 $\mathrm{mg} / \mathrm{l}$ para abril y junio de 2018, sobrepasando los LMP emanados por el D.S. No 010-2018 (MINAM, 2018). (Figura 4). Por otro lado, la $\mathrm{DBO}_{5}$ en el efluente estuvo en el rango entre $1925 \mathrm{mg} / \mathrm{l}$ y $9675 \mathrm{mg} / \mathrm{l}$ para abril y diciembre 2018 (Figura 5), que sobrepasan los límites máximos permisibles según legislación sobre calidad de aguas de Ecuador, (2006), Legislación de Venezuela (1995) y el D.S. N 010-2008 (PRODUCE, n.d.) -ya derogado en Perú-, así mismo las bases volátiles nitrogenadas (TVN) los cuales son un indicador de frescura del recurso pesquero, sus concentraciones estuvieron en el rango de $20.18 \mathrm{mg} / \mathrm{l}$ en enero 2019 y 27.98 en noviembre 2018 (Figura 6).

De acuerdo a IMARPE 2018 (Instituto del Mar del Perú, n.d.-a), en el monitoreo realizado en el cuerpo receptor (el mar), en mayo del año 2018 en pleno procesamiento de la industria de harina y aceite de pescado en Huacho, las condiciones de calidad del agua de mar tuvieron los siguientes resultados: La Temperatura superficial del mar (TSM) se presentó en el intervalo de 17.0 - 18.1, La concentración de grasas y aceites en mayo de 2018 se presentó entre $0.3-0.4 \mathrm{mg} / \mathrm{l}$. Las concentraciones de oxígeno disuelto en la superficie del agua de mar de Huacho en el mes de mayo de 2018, estuvieron en el rango de $4.56 \mathrm{mg} / \mathrm{l}$ y $9.5 \mathrm{mg} / 1.4 .56 \mathrm{mg} / \mathrm{l}$ y $9.5 \mathrm{mg} / \mathrm{l}$. Estas concentraciones llegan al nivel de saturación. Por otro lado, las concentraciones de $\mathrm{DBO}_{5}$ en este mismo periodo las concentraciones oscilaron entre $0.73 \mathrm{mg} / \mathrm{l}$ y $3.51 \mathrm{mg} / \mathrm{l}$. (Tabla 2).

Tabla 2. Calidad del agua de mar. Huacho, mayo 2018

\begin{tabular}{cccccc}
\hline Estación & $\begin{array}{c}\text { TSM } \\
{ }^{\circ} \mathrm{C}\end{array}$ & $\begin{array}{c}\text { ODS } \\
\mathrm{mg} / \mathrm{l}\end{array}$ & $\begin{array}{c}\text { SST-S } \\
\mathrm{mg} / \mathrm{l}\end{array}$ & $\begin{array}{c}\text { DBO5 } \\
\mathrm{mg} / \mathrm{l}\end{array}$ & $\begin{array}{c}\text { Aceites y } \\
\text { grasa } \\
\mathrm{mg} / \mathrm{l}\end{array}$ \\
\hline 6 & 17.5 & 4.56 & 44.25 & 3.51 & 0.4 \\
7 & 17.5 & 6.6 & & & \\
8 & 17.5 & 7.25 & & & \\
$8 \mathrm{~A}$ & 17.5 & 9.5 & 52.25 & 0.73 & \\
9 & 17.4 & 6.88 & & & \\
10 & 17.5 & 6.54 & & & \\
11 & 18.1 & 8.37 & & & $<0.3$ \\
$11 \mathrm{~A}$ & 17.7 & 5.42 & 43.5 & 0.33 & \\
12 & 17 & 4.89 & & & \\
13 & 17.4 & 6.39 & 63.75 & 0.78 & \\
Ho1 & 17.3 & 7.79 & & 1.96 & \\
Ho2 & 17.8 & 10.18 & & 2.21 & \\
Ho3 & 17.9 & 10.33 & & 3.19 & \\
Ho4 & 17.7 & 9.13 & & 3.19 & \\
\hline Fuente: IMARPE, 2018 (Instituto del Mar del Perú, n.d.-a) &
\end{tabular}

Fuente: IMARPE, 2018 (Instituto del Mar del Perú, n.d.-a)

Asimismo según IMARPE 2019 (Instituto del Mar del Perú, n.d.-b), durante el mes de mayo de 2019, también en época de procesamiento industrial pesquero, las condiciones 


\section{ACEITES Y GRASAS (A \& $\mathrm{G}$ ) en $\mathrm{mg} / \mathrm{l}$}

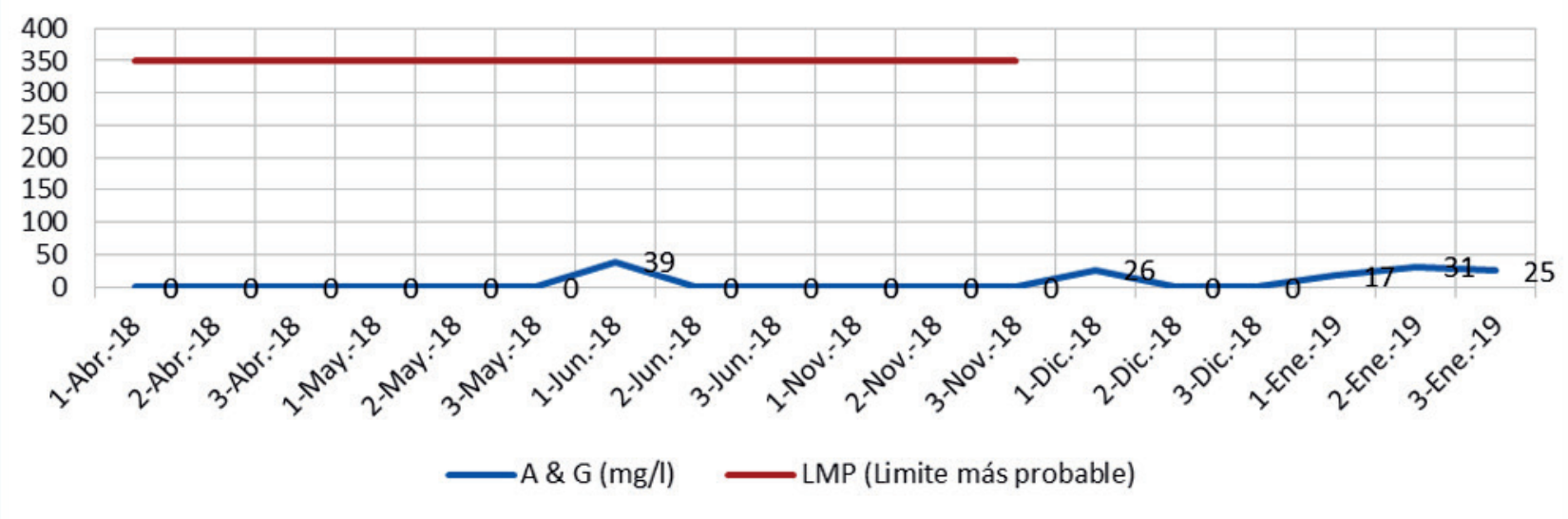

Figura 3. Aceites y grasas en el efluente industrial tratado vs LMP. Exalmar. 2018-2019.

Fuente: Elaboración propia

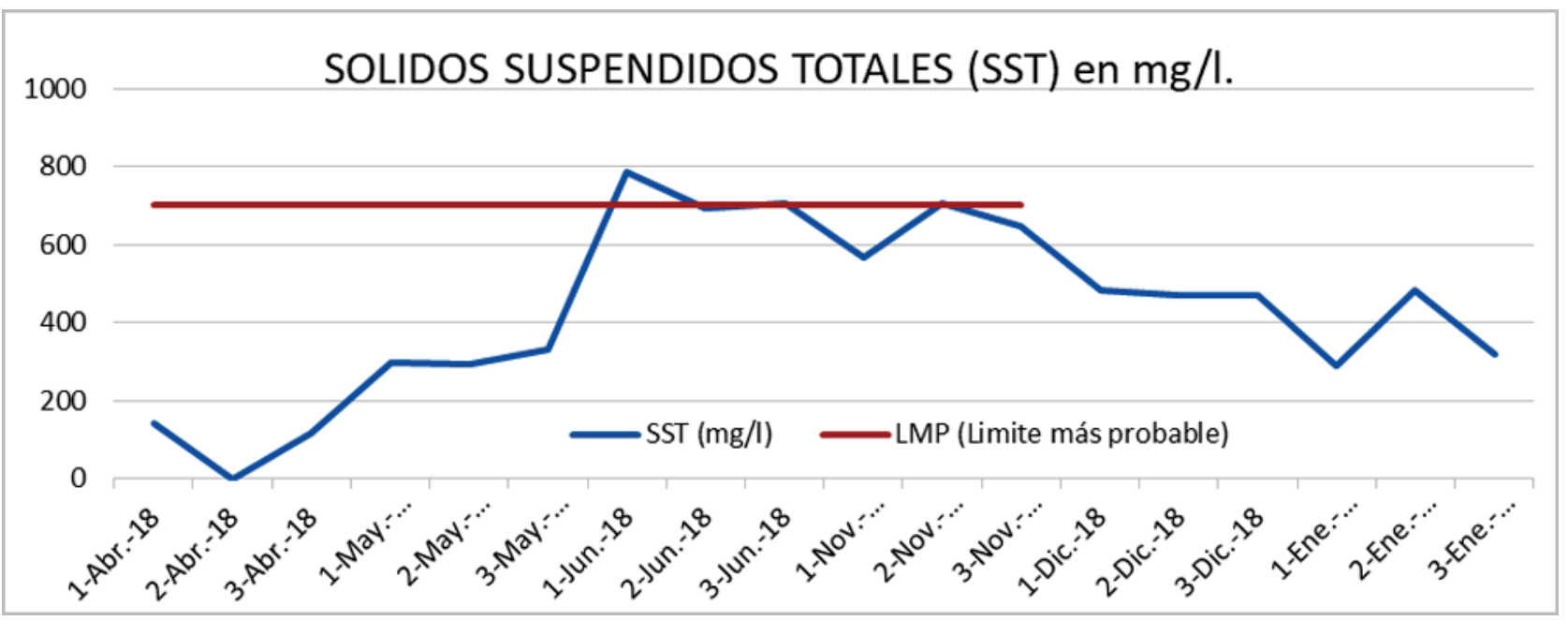

Figura 4. Solidos suspendidos totales (mg/l) en el efluente industrial tratado vs LMP. Exalmar. 2018-2019.

Fuente: Elaboración propia

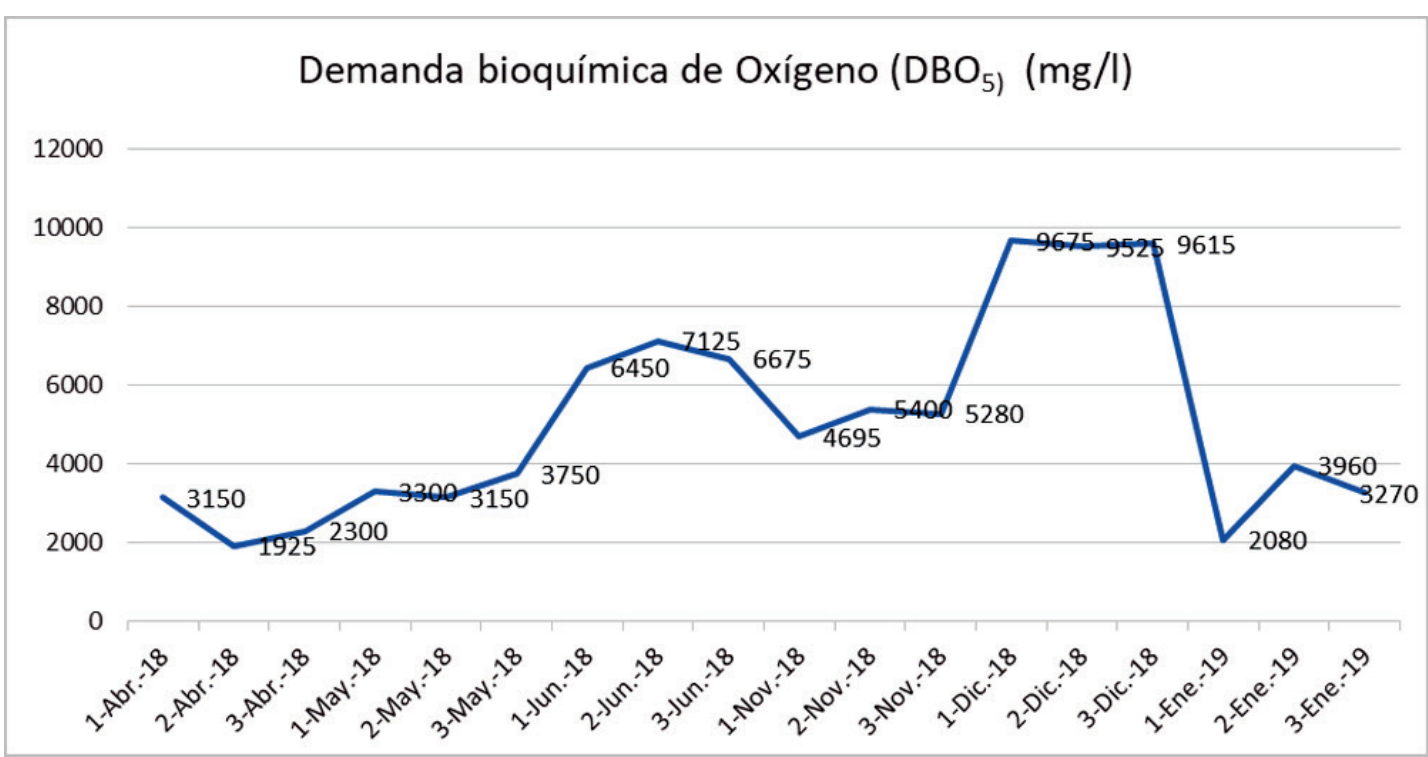

Figura 5. Demanda bioquímica de Oxigeno (mg/l) en el efluente industrial tratado. Exalmar. 2018-2019. Fuente: Elaboración propia. 


\section{TVN (mg/100g)}

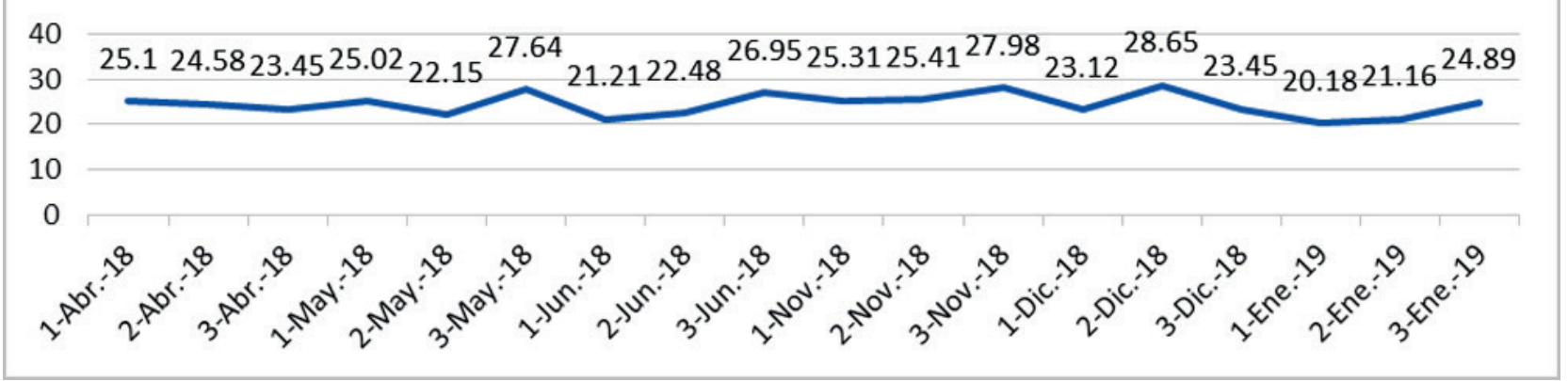

Figura 6.TVN Efluente industrial tratado. Exalmar.2018-2019.

Fuente: Elaboración propia

de calidad del agua de mar siguieron el mismo patrón del mes de mayo de 2018, donde la temperatura superficial del mar osciló de $17.4^{\circ} \mathrm{C}$ y $18.0^{\circ} \mathrm{C}$, la concentración de grasas $\mathrm{y}$ aceites estuvo entre $0.30-0.40 \mathrm{mg} / \mathrm{l}$. Por otra parte, la concentración de sólidos suspendidos totales estuvo entre $43.10 \mathrm{mg} / 1$ y $63.75 \mathrm{mg} / \mathrm{l}$. Las concentraciones del oxígeno disuelto estuvieron en el rango de $4.56 \mathrm{ml} / 1$ y $8.37 \mathrm{ml} / \mathrm{l}$ y la demanda bioquímica de oxígeno estuvo entre 0.73 $\mathrm{mg} / \mathrm{l}$ y $3.51 \mathrm{mg} / \mathrm{l}$. (Tabla 3). Estos valores encontrados en las evaluaciones ambientales durante mayo de 2019 en el ambiente marino de Huacho, están dentro los de los estándares de calidad de aguas (ECAs); sin embargo pueden verse afectada por la carga orgánica.

\section{Discusión}

Según UNEP (2004), el análisis del ciclo de vida establece la forma y tiene influencia en cada fase del proceso, sopesa las ventajas y desventajas, y contribuye en la economía, el ambiente y la población.

Al analizar los aspectos ambientales identificados en las empresas pesqueras TASA, Hyduck, Exalmar y Productos del Campo, ubicadas en Huacho, Carquín y Vegueta, éstas, coinciden con Bayón Martínez (2006), quien identifica y evalúa los aspectos ambientales de plantas pesqueras en Callao e indica en su estudio de investigación que la industria de harina y aceite de pescado genera grandes volúmenes de efluentes industriales, caracterizados por su elevado contenido. Por su parte, Cabana Huaman (2018), encontró que los PAMAs, adicional a su fin de minimizar el impacto del proceso productivo en la industria de pescado, también permite incrementar la productividad.

De esta investigación realizada, se confirma que la operación de descarga del pescado es uno de los principales aspectos ambientales que generan contaminación en el agua de mar por el volumen de sanguaza que vierten. Asimismo, el principal impacto de la actividad industrial de la harina y aceite de pescado está asociado con los grandes volúmenes vertidos de carga orgánica que generan una rápida disminución de oxígeno disuelto en la columna de agua y sedimentos marinos y que afectan a las comunidades biológicas. Esta situación se ve magnificada por las características de la bahía de Vegueta, Carquín y Huacho que es de forma semicerrada donde se ubican las plantas pesqueras y a la lenta circulación del agua y a sus altos tiempos de residencia; esto hace que estas bahías tengan una escasa capacidad de carga (asimilación) y de dilución del cuerpo receptor (mar).

Ambrosio \& Zar (2017), coincide con esta investigación, al concluir que el procesamiento industrial pesquero tiene una importancia económica pero generan problemas que sobrepasan la capacidad de gestión, concluyendo que los impactos ambientales significativos se producen por falta de tecnologías para la recuperación de la calidad de los vertidos y la presencia de fábricas de harina de pescado no integral.

Por su parte, al comparar las condiciones ambientales del mar con (Zuta \& Guillén, 1970), los valores son representativos del agua costera fría (ACF) del mar peruano, sin embargo la presencia de aguas residuales de calderos y de los residuos líquidos industriales generan un impacto ecológico significativo; así mismo pueden acelerar las reacciones químicas, reducen la solubilidad de los gases, generan cambios en la coloración del agua, se intensifican los olores y sabores, entre otros, Seoanez Calvo (1998).

Las concentraciones encontradas de grasas y aceites entre $0.3-0.4 \mathrm{mg} / \mathrm{l}$; si bien en este periodo las concentraciones de grasas y aceite son relativamente bajas, pero esto genera intensos "halos" de grasas en la capa superficial del agua, así, el oxígeno presente para la oxidación de la materia orgánica, es consumido y produce cambios en el incremento del $\mathrm{pH}$ y la muerte de flora y fauna. Existe una relación entre la concentración del oxígeno disuelto en el agua (OD) y su grado de contaminación (Raffo Lecca \& Ruiz Lizama, 2014). Estas condiciones ambientales registradas frente a Vegueta, Carquín y Huacho, guardan relación con las condiciones ambientales registradas en el mar peruano, Instituto del Mar del Perú (IMARPE 2018, 2019), registrándose el avance de aguas cálidas hacia la costa norte-centro. La zona costera se caracterizó por la presencia de aguas menores de $22{ }^{\circ} \mathrm{C}$ con valores mínimos de $19,6{ }^{\circ} \mathrm{C}$ al norte del Callao, con valores de salinidad de 35,2 UPS, con predominio de condiciones cálidas de magnitud débil 
Tabla 3. Calidad del agua de mar. Huacho, mayo 2019

\begin{tabular}{|c|c|c|c|c|c|c|c|}
\hline Estación & $\begin{array}{l}\text { TSM } \\
{ }^{\circ} \mathrm{C}\end{array}$ & $\begin{array}{l}\text { ODS } \\
\mathrm{mg} / \mathrm{l}\end{array}$ & $\begin{array}{c}\text { SST-S } \\
\mathrm{mg} / \mathrm{l}\end{array}$ & $\begin{array}{r}\text { DBO5 } \\
\mathrm{mg} / \mathrm{l}\end{array}$ & $\begin{array}{c}\text { Aceites y } \\
\text { grasas } \\
\text { mg/l }\end{array}$ & $\begin{array}{c}\text { Nitratos } \\
\mathrm{mg} / \mathrm{l}\end{array}$ & $\begin{array}{c}\text { Nitritos } \\
\mathrm{mg} / \mathrm{l}\end{array}$ \\
\hline 6 & 17.5 & 4.56 & 44.25 & 3.51 & 0.4 & 0.18 & 0.02 \\
\hline 7 & 17.5 & 6.6 & & & & 0.13 & 0.02 \\
\hline 8 & 17.5 & 7.25 & & & & 0.16 & 0.01 \\
\hline $8 \mathrm{~A}$ & 17.5 & 9.5 & 52.25 & 0.73 & & 0.17 & 0.02 \\
\hline 9 & 17.4 & 6.88 & & & & 0.18 & 0.01 \\
\hline 10 & 17.5 & 6.54 & & & & 0.15 & 0.02 \\
\hline 11 & 18.1 & 8.37 & & & & 0.14 & 0.02 \\
\hline $11 \mathrm{~A}$ & 17.7 & 5.42 & 43.5 & 0.33 & $<0.3$ & 0 & 0.02 \\
\hline 12 & 17 & 4.89 & & & & 0 & 0.02 \\
\hline 13 & 17.4 & 6.39 & 63.75 & 0.78 & $<0.3$ & 0 & 0.01 \\
\hline
\end{tabular}

Fuente: IMARPE, 2019 (Instituto del Mar del Perú, n.d.-b)

en la zona norte-centro del mar peruano, notándose el leve incremento de la temperatura principalmente mar adentro frente a la costa centro-sur.

\section{CONCLUSIONES}

El análisis del ciclo de vida (ACV), es una herramienta que sirve para identificar y evaluar los aspectos e impactos ambientales en la industria de harina y aceite de pescado, con esto se logra posibles áreas de mejora y en los diseños de nuevos productos o innovaciones de los ya existentes.

Los principales aspectos ambientales significativos identificados en el procesamiento industrial de harina de pescado son: desembarco, recepción y almacenamiento de Engraulis ringens (anchoveta), cocción, desaguado, prensado, separación, centrifugación, molienda, secado, dosificación de antioxidante, ensaque, generación de energía, evaporación de líquido de cola, tratamiento de residuos líquidos industriales (RILs), mantenimiento de maquinaria.

En el balance de materia y energía para una planta de harina y aceite de pescado de $84 \mathrm{TM} /$ hora en una planta, motivo de estudio, el rendimiento de producción es de pescado /harina: 4.150 y para pescado /aceite: 6.307

El principal impacto de la actividad industrial de la harina y aceite de pescado está asociado con los volúmenes vertidos de agua residual que contiene carga orgánica, generan una rápida disminución de oxígeno disuelto.

Durante los años 2018-2019, la concentración de grasas y aceites en los residuos líquidos industriales de las plantas de harina de pescado de Huacho, Carquín y Vegeta estuvieron por debajo de los LMP y en el caso de sólidos suspendidos totales se registran concentraciones de hasta $881 \mathrm{mg} / \mathrm{L}$ sobrepasando el LMP. Asimismo, los valores de concentraciones de demanda bioquímica de oxígeno llegaron a un máximo de $9150 \mathrm{mg} / \mathrm{l}$; estas concentraciones son relativamente muy altas, si comparamos con el D.S.
$\mathrm{N}^{\circ}$ 010-2008 (PRODUCE, n.d.), ya derogada por el D.S. 010-2018-PRODUCE, (no considera la $\mathrm{DBO}_{5}$ ) y normas internacionales sobre calidad de aguas marinas de Ecuador y Venezuela.

\section{REFERENCIAS}

Ambrosio, J. M., \& Zar, M. A. (2017). Procesamiento pesquero, disposición de residuos e impacto ambiental. https://www.researchgate.net/profile/ Marcelo_Ambrosio2/publication/266409250_ PROCESAMIENTO PESQUERO DISPOSICION ${ }_{-}^{-}$ DE_RESIDUOS_E_IMPACTO_AMBIENTAL/ links/55c11add08ae9289a09d0063.pdf

Bayón Martínez, P. (2006). Biblioteca Virtual de Filosofía y Pensamiento Cubanos - Educación ambiental, participación $y$ transformación social sostenible en Cuba. Revista Interface. Brasil. Nro. 3, 3. http://biblioteca.filosofia.cu/php/ export.php?format $=$ htm\&id $=2335 \&$ view $=1$

Cabana Huaman, N. T. (2018). Influencia del programa de adecuación al medio ambiente en el incremento de la productividad de la industria de harina de pescado de la industria pesquera 1313 S.A. Tesis Para Optar El Título de Ingeniero Químico. Universidad Nacional de Trujillo. http:// dspace.unitru.edu.pe/handle/UNITRU/10523

D.S. $\mathrm{N}^{\circ}$ 010-2008-PRODUCE. (n.d.). Modifica el Decreto Supremo que aprueba límites máximos permisibles (LMP) para la industria de harina y aceite de pescado. 2011. Retrieved July 21, 2020, from moz-extension:// af9c8ffb-6ba6-4457-980e-9fee00c031c9/enhanced-reader. html?openApp\&pdf=https $\% 3 \mathrm{~A} \% 2 \mathrm{~F} \% 2 \mathrm{Fwww}$. oz-peru. com $\% 2$ Fwp-content $\% 2$ Fuploads $\% 2$ F2016\%2F09\%2FD.S .N-010-2008.pdf

D.S. No 010-2018-MINAM. (2018). Aprueban Límites Máximos Permisibles para Efluentes de los Establecimientos Industriales Pesqueros de Consumo Humano Directo e Indirecto. SINIA | Sistema Nacional de Información Ambiental. https://sinia.minam.gob.pe/normas/apruebanlimites-maximos-permisibles-efluentes-establecimientos 
IMARPE-Instituto del Mar del Perú. (2018). Boletín semanal oceanográfico y biológico pesquero. Año $3, \quad N^{\circ} \quad 52$. moz-extension://af9c8ffb-6ba64457-980e-9fee 00c031c9/enhanced-reader. html?openApp\&pdf=http $\% 3 \mathrm{~A} \% 2 \mathrm{~F} \% 2 \mathrm{Fwww}$.imarpe. pe\%2Fimarpe $\% 2$ Farchivos\%2Fboletines\%2Fimarpe_ bsobp_522018.pdf

IMARPE-Instituto del Mar del Perú. (2019). Boletín semanal oceanográfico y biológico pesquero. Año $4, \quad N^{\circ}$ 52. moz-extension://af9c8ffb-6ba64457-980e-9fee $00 \mathrm{c} 031 \mathrm{c} 9 / \mathrm{enh}$ anced-reader. html?openApp\&pdf=http $\% 3 \mathrm{~A} \% 2 \mathrm{~F} \% 2 \mathrm{Fwww}$.imarpe. pe $\% 2$ Fimarpe $\% 2$ Farchivos $\% 2$ Fboletines $\% 2$ Fimarpe bsobp 522019.pdf

ISO 14040:2006. CTN 150 - Gestión Ambiental. (2006). UNEEN ISO 14040:2006. Gestión ambiental Análisis del ciclo de vida Principios y marco de referencia (p. 29). https:// www.iso.org/obp/ui\#iso:std:iso:14040:ed-2:v1:es

Miranda, E. (2018). Propuesta de un Sistema de Gestión Ambiental basado en la ISO 14001:2004 para la planta de harina de pescado en la empresa Pesquera Cantabaris S.A. en el Distrito de Coishco, Ancash, Perú [Universidad Nacional del Santa]. http://repositorio.uns.edu.pe/handle/ UNS/3150
Raffo Lecca, E., \& Ruiz Lizama, E. C. (2014). Caracterización de las aguas residuales y la demanda bioquímica de oxígeno. Industrial Data, 17(1), 71. https://doi.org/10.15381/idata. v17i1.12035

Seoanez Calvo, M. (1998). Medio ambiente y desarrollo: manual de gestión de los recursos en función del medio ambiente (Ediciones Mundi Prensa (Ed.)). https://dialnet.unirioja.es/ servlet/libro?codigo $=104677$

Talledo Espinosa, S. L. (2010). Situación y perspectiva de la harina de pescado: Caso peruano de 1980-2007. https:// cybertesis.unmsm.edu.pe/handle/20.500.12672/2313

UNEP. (2004). United Nations Environment Programme Annual Evaluation Report Evaluation and Oversight Unit. September. http://wedocs.unep.org/bitstream/ handle/20.500.11822/356/UNEP_Annual_Evaluation_ Report_2004.pdf?sequence $=1$ \&isAllowed $=y$

Zuta, S., \& Guillén, O. (1970). Oceanografía de las aguas costeras del perú. In Boletin Inst. Mar. Perú-Callao (Vol. 2, Issue 5, pp. 157-324). IMARPE. http://biblioimarpe.imarpe.gob.pe/ handle/123456789/949 